\title{
Optimization for sensory and nutritional quality of a mixed berry fruit juice elaborated with coconut water
}

\author{
Maria Cecília Evangelista Vasconcelos SCHIASSI ${ }^{1}$, Cynara dos Santos CARVALHO ${ }^{1}$, Amanda Maria Teixeira LAGO ${ }^{1}$ (D), \\ Paula Nogueira CURI ${ }^{1}$, Rafael PIO ${ }^{1}$, Fabiana QUEIROZ ${ }^{1}$, Jaime Vilela de RESENDE ${ }^{1}$, Vanessa Rios de SOUZA ${ }^{1 *}$
}

\begin{abstract}
A new juice market, consisting of mixtures of fruits, is expanding in the beverage segment, in order to increase even more the nutritional and sensory characteristics. In addition, in the preparation of juices, the option exists to replace water with coconut water. The aim of this study was to develop and optimize mixed juices based on coconut water and berries (strawberry, blackberry, and red raspberry), through the mixture design, desirability function, and response surface methodology. Mixed juices were evaluated by rheological, physical, physicochemical, sensory, and nutritional characteristics. The treatments produced with strawberry (50\% or 100\%) were preferred among the tasters, and the juices elaborated using blackberry contributed to higher viscosity, antioxidant activity, phenolic compounds, and total anthocyanins. According to optimization, the mixed juices should contain $50-60 \%$ strawberry, $40 \%$ blackberry, and 0-10\% raspberry. Thus, the mixed juices produced from these fruits have better characteristics than the juice of only one fruit type.
\end{abstract}

Keywords: mixture design; desirability function; sensory acceptance; mixed fruit juice.

Practical Application: The ideal mix of berry fruits increases the nutritional and sensory value of the juice.

\section{Introduction}

Among the fruits, 'berries' or 'red fruit' are characterized as small, with juicy pulp of sweet or bitter taste and colouration that is usually red, purple or blue (Hidalgo \& Almajano, 2017). Recently, the consumption of fruits, especially berries, has been increasing due to its high nutritional value, mainly anthocyanin and antioxidant activity (Souza et al., 2014b; Olas, 2018). Berry consumption provides improvement in various diseases (disorders in neuronal communication and inflammatory responses), cognitive functions (improved memory in older adults), and reduces incidence of cardiovascular disorders, inflammatory processes and cancer (Manganaris et al., 2014; Gomes-Rochette et al., 2016).

Berries can be consumed in fresh or processed form, and in this group, strawberry (Fragaria $\mathrm{x}$ ananassa), blackberry (Rubus spp.) and red raspberry (Rubus idaeus) are highly appreciated for their delicate texture, sharp colour and unique flavour. These fruits present high postharvest losses due to softness, over-ripening and pathogen attack (Manganaris et al., 2014). In addition, high levels of water make them susceptible to enzymatic or microbial degradation (Yousefi et al., 2013). Thus, a way to avoid these losses is through the product development of juices, jellies, jam, liqueurs and ice creams.

In the beverages segment, the fruit processing industries are developing differentiated products composed of two or more fruits, and this market is expanding increasingly (Souza et al., 2012; Pelegrine et al., 2015; Curi et al., 2019; Schiassi et al., 2019). The development of mixed juices is a viable alternative available to the industry, with the purpose of elaborating exclusive and healthier drinks because the combination of fruits can enhance nutritional characteristics (increase in the content of vitamins, minerals and soluble solids of the product) and sensorial quality (improving colour and consistency and balancing weak, mild and strong flavours, mainly with high acidity, astringency, or bitterness of certain fruits), thereby adding value to the final product (Sobhana et al., 2015; Curi et al., 2017; Schiassi et al., 2018).

In the processing of fruit juices, fruit nectars, and mixed fruit juice/nectars, a high proportion of potable water is used (Food and Agriculture Organization of the United Nations, 2005). As the trend in the world market is a quest for beverages of mixed fruits with good sensory, nutritional, functional and therapeutic properties (Chauhan et al., 2014), the development of a mixed juice with coconut water from coconuts (Cocos nucifera L.), replacing potable water, is an excellent alternative (Prado et al., 2015). However, literature on beverages prepared with coconut water is scarce.

Over the years, the market for natural fruit beverages has grown sharply, due to the current trend of consumers seeking safe, good-quality, healthy, nutritionally balanced, and ready-toconsume food and beverages has been verified, mainly with high content of bioactive compounds (functional) (Newhart, 2019; Schiassi et al., 2018). For this purpose, the aim of this study was to optimize a berry fruit mixed juice elaborated with coconut water, based on the nutritional and sensory quality, through response surface methodology and desirability function, as well as 
to verify the influence of fruits on the physical, physicochemical, nutritional, and sensorial characteristics of the final product.

\section{Materials and methods}

\subsection{Ingredients}

The juices were formulated using natural green coconut water (Cocus nucifera L.), strawberry (Fragaria x ananassa), blackberry (Rubus spp.), red raspberry (Rubus idaeus), and sucralose. Strawberry and coconut were obtained from a local grocery store located in Lavras (MG, Brazil), and blackberry and red raspberry were obtained directly from the orchard of the Federal University of Lavras (UFLA), all at the maturation stage. The site is at geographic coordinates $21^{\circ} 14^{\prime} \mathrm{S}, 45^{\circ} 00^{\prime} \mathrm{W}$ and $841 \mathrm{~m}$ altitude, classified as Cwa climate, i.e., subtropical climate, with cold and dry winters and hot and wet summers (Alvares et al., 2013). Fruits were selected to avoid those that were physically damaged and washed, sanitized in $2 \%$ chlorinated solution for $30 \mathrm{~min}$ and maintained at $4{ }^{\circ} \mathrm{C}$ until processing time.

\subsection{Experimental design}

In this study, the Simplex Centroid mixture design (Cornell, 2002) was applied with the purpose of evaluating the effects and optimizing the strawberry, blackberry, and red raspberry proportions in the juices, based on sensory and nutritional characteristics. Seven juice formulations with different concentrations were elaborated, as described in Table 1.

\subsection{Juice processing}

Initially, a pre-test was conducted to determine the best proportions of coconut water, pulp and sucralose used in the formulation of isolated fruit juices, according to the Legislation, Decree No. 6.871/2009 (Brasil, 2009). This legislation requires fruit juice to contain a minimum of $30 \%$ (w/w) pulp; thus, all juices were elaborated with $50 \%$ pulp and $50 \%$ coconut water. The juice of each of the isolated fruits was elaborated, and later, these juices were combined according to the mixture design. After all samples were obtained, these were sweetened by adding $0.05 \mathrm{~g}$ of sucralose to each $1 \mathrm{~L}$ of juice. An LS-4 industrial blender with $4.0 \mathrm{~L}$ capacity at a speed of $3500 \mathrm{rpm}$ (Metalúrgica Siemsen Ltda, Brusque, Brazil), was used to elaborated the juices. The juices were homogenized and then bottled in sterile $500 \mathrm{~mL}$ glass bottles and stored under refrigeration at $4-7^{\circ} \mathrm{C}$. The entire process was

Table 1. Composition of berry juice formulations according to the Simplex Centroid mixture design.

\begin{tabular}{cccc}
\hline \multirow{2}{*}{ Treatments } & \multicolumn{3}{c}{ Variables } \\
\cline { 2 - 4 } & $\begin{array}{c}\text { Strawberry } \\
(\%)\end{array}$ & $\begin{array}{c}\text { Red Raspberry } \\
(\%)\end{array}$ & $\begin{array}{c}\text { Blackberry } \\
(\%)\end{array}$ \\
\hline 1 & 100 & 0 & 0 \\
2 & 0 & 100 & 0 \\
3 & 0 & 0 & 100 \\
4 & 50 & 50 & 0 \\
5 & 50 & 0 & 50 \\
6 & 0 & 50 & 50 \\
7 & 33 & 33 & 34 \\
\hline
\end{tabular}

done strictly following good manufacturing practices, and the juice was served to the tasters within $24 \mathrm{~h}$ after its elaboration. Physicochemical, physical, and rheological analyses were performed soon after juice preparation. For the analysis of antioxidant activity and bioactive compounds, extracts were prepared after $24 \mathrm{~h}$ and then analysed.

\subsection{Rheological analysis}

Rheological behaviour of the samples was determined at $10{ }^{\circ} \mathrm{C}$ (temperature of juice consumption) using a rheometer (HAAKE ReoStress 6000, Thermo Scientific, Karlsruhe, Germany) equipped with a thermostatic bath (HAAKE A10, Thermo Scientific) and a universal temperature control system (HAAKE UTM Controller, Thermo Scientific). The measurements were carried out using concentric cylindrical geometry sensors (cup CCB25 DIN, rotor CC25 DIN Ti, gap of $5.3 \mathrm{~mm}$ ). Samples were analysed in 3 replicates, using a volume of $16.1 \mathrm{~mL}$ for each replicate. To eliminate thixotropy (the influence of time on the solution flow behaviour), each sample was subjected to three continuous shear rate ramps (rising, downward, and rising) ranging from 0 to $300 \mathrm{~s}^{-1}$ for $3 \mathrm{~min}$ for each curve. The Newton's law (Equation 1), Power Law (Equation 2), and Herschel-Buckley (Equation 3) models were fitted to experimental data of the second rising curve (flow curve).

$$
\begin{aligned}
& \sigma=\mu \dot{\gamma} \\
& \sigma=k \dot{\gamma}^{n} \\
& \sigma=\sigma_{o}+k \dot{\gamma}^{n}
\end{aligned}
$$

where $\sigma$ is the shear stress $(\mathrm{Pa}) ; \mu$ is the Newtonian viscosity $(\mathrm{Pa} \cdot \mathrm{s}) ; \dot{\gamma}$ is the shear rate $\left(\mathrm{s}^{-1}\right) ; k$ is the consistency index $\left(\mathrm{Pa} \cdot \mathrm{s}^{\mathrm{n}}\right)$; $n$ is the flow behaviour index; and $\sigma_{o}$ is the yield stress $(\mathrm{Pa})$.

\subsection{Physicochemical and physical analysis}

To characterize the different juice formulations, the $\mathrm{pH}$, titratable acidity, and soluble solids were determined according to the method described by Instituto Adolfo Lutz (2008). The instrumental colour $\left(\mathrm{L}^{*}, \mathrm{C}^{*}\right.$, and $\left.\mathrm{h}^{*}\right)$ was determined according Gennadios et al. (1996) using a colourimeter instrument (model CM5, Konica Minolta Spectrophotometer, São Paulo, SP, Brazil) operating in the CIELAB opponent colour system.

\subsection{Sensory analysis}

The project was approved by the local ethics committee (number 1.755.177) prior to performing the analysis. An acceptance test was conducted for the evaluation of the sensory attributes (colour, flavor, consistency and overall liking) using a 9-point structured hedonic scale ( 1 = extremely disliked; $9=$ extremely liked) (Stone et al., 2012). For the sensory test, one-hundred consumers (60 women and 40 men), age 18 to 60 years, were randomly recruited. Each participant evaluated the seven juices in two sessions (i.e., 4 samples in the first session and 3 samples in the second session). Samples (approximately $15 \mathrm{~mL}$ ) held at $10{ }^{\circ} \mathrm{C}$ were offered in $50 \mathrm{~mL}$ disposable plastic cups. Cups were 
coded with 3-digit numbers drawn from a table of random numbers and presented in a balanced order (MacFie et al., 1989). The sensory test was carried out in individual booths under white light in a quiet environment, according to local ethical standards.

\subsection{Antioxidant activity and bioactive compounds}

Sample juices were subjected to antioxidant activity (ABTS and DPPH methods), phenolic compounds, total monomeric anthocyanin content and ascorbic acid content. The extracts for the analysis of antioxidant activity and phenolic compound were prepared according to the method described by Larrauri et al. (1997). The ABTS method, followed the procedure developed by Re et al. (1999), where the absorbance was read at a wavelength of $734 \mathrm{~nm}$ using a spectrophotometer (SP-22, VIS 325-1000 nm, Biospectro, Taboão da Serra, SP, Brazil), and the results were expressed as micromoles of Trolox-equivalent per gram of fresh weight ( $\mu \mathrm{mol}$ of TEs/g f.w.). DPPH free radical scavenging ability was carried out according to Brand-Williams et al. (1995). The absorbance readings in a spectrophotometer at $515 \mathrm{~nm}$, and the results were expressed in $\mathrm{EC}_{50}$ (g f.w./g DPPH).

Phenolic compounds were estimated following the method of Folin-Ciocalteu, as described by Waterhouse (2002), the absorbance was read at a wavelength of $750 \mathrm{~nm}$, and results were expressed as $\mathrm{mg}$ of gallic acid equivalent per $100 \mathrm{~g}$ f.w. (mg GAEs/100 g f. w.). The total monomeric anthocyanin content was determined using the differential $\mathrm{pH}$ method according to Wrolstad (1993). The absorbance was measured at $510 \mathrm{~nm}$ and $700 \mathrm{~nm}$ in buffer ( $\mathrm{pH} 1.0$ and 4.5, respectively), and the results were expressed as g of cyanidin-3-glucoside equivalent per $100 \mathrm{~g}$ f.w. (mg of cyanidin 3-glucoside equivalent/100 $\mathrm{g}$ f.w.). The ascorbic acid content (vitamin $\mathrm{C}$ ) of each juice was evaluated using the colourimetric method with 2,4-dinitrophenylhydrazine (DNPH) according to Strohecker \& Henning (1967). The results were expressed as mg of ascorbic acid per $100 \mathrm{~g}$ f.w. (mg/100 g f.w.).

\subsection{Statistical analysis}

The different sample effects were evaluated by analysis of variance (ANOVA) and means testing (Tukey, $P \leq 0.05)$ using SensoMaker software v. 1.8 (Pinheiro et al., 2013). Rheological models were fitted to the experimental data of the flow curves using the statistical package Statistical Analysis System
(SAS Institute, 2016), and the graphs were plotted using SigmaPlot 11.0 software (SYSTAT Software Inc. (2008), California, USA).

For easy viewing of sensory acceptance of the juices, which was based on the individual response of each consumer and correlated with the physicochemical parameters and instrumental colour, an external preference map of a 3-way arrangement was obtained through the software SensoMaker v. 1.8 (Nunes et al., 2011). A data set was arranged in a matrix with $i$ lines ( 7 samples) and $j+m$ columns (100 consumers +6 physicochemical and instrumental colour). These matrices were organized according to $k$ sensory attributes (colour, flavor, consistency and overall liking), resulting in an external preference map of a 3-way arrangement (i, j $+\mathrm{m}$ and $\mathrm{k}$ ) (Nunes et al., 2011).

Principal component analysis (PCA) was applied for the antioxidant capacity and bioactive compounds data to facilitate the visualization of results. The data were arranged in a matrix of $i$ rows ( 7 samples) and $j$ columns ( 5 antioxidants compounds and bioactive compounds). Data were standardized (correlation matrix) and submitted to PCA using SensoMaker v. 1.8 software (Pinheiro et al., 2013).

To optimize, sensory parameters were transformed into desirability functions obtained thought response surface methodology analysis (RSREG), based on the type of response - Larger-The-Best (LTB) - in order to optimize the fruit juice, with a specific parameter ( $r$ ) of 1.0. Based on the predicted model equation, a contour curve of the desirability function was generated. The optimum region was obtained, which originates a juice with better sensory characteristics, and analysis of variance was used to evaluate the model-fitted data significance; the triangular contour graphs generated from the polynomial equations were created using Chemoface 1.6 software (Nunes et al., 2012).

\section{Results and discussion}

\subsection{Rheological analysis}

Among the models used to describe the rheological behaviour of fruit juice treatments, the Power Law model ( $k$, consistency index and $n$, flow behaviour index) presented the best adjustments to the experimental data, with a high coefficient of determination $\left(0.9125 \leq \mathrm{R}^{2} \leq 0.9954\right)$ and low root mean square error $(0.1453 \leq \mathrm{RMSE} \leq 0.5360)$ values (Table 2).

Table 2. Rheological parameters obtained for fruit juices at $10{ }^{\circ} \mathrm{C}$.

\begin{tabular}{|c|c|c|c|c|}
\hline \multirow{2}{*}{ Treatments } & \multicolumn{4}{|c|}{ Power Law } \\
\hline & $k$ & $n$ & RMSE & $\mathrm{R}^{2}$ \\
\hline $\mathrm{F} 1$ & $0.6144^{\mathrm{a}}( \pm 0.0245)$ & $0.4472^{\mathrm{d}}( \pm 0.0041)$ & 0.5360 & 0.9150 \\
\hline $\mathrm{F} 2$ & $1.2394^{\mathrm{e}}( \pm 0.0579)$ & $0.2788^{\mathrm{a}}( \pm 0.0069)$ & 0.3074 & 0.9762 \\
\hline F3 & $1.8484^{\mathrm{g}}( \pm 0.3686)$ & $0.3147^{\mathrm{b}}( \pm 0.0357)$ & 0.3675 & 0.9694 \\
\hline $\mathrm{F} 4$ & $0.7816^{\mathrm{b}}( \pm 0.1705)$ & $0.4385^{\mathrm{d}}( \pm 0.0014)$ & 0.1947 & 0.9708 \\
\hline F5 & $0.9527^{c}( \pm 0.0395)$ & $0.4000^{c}( \pm 0.0077)$ & 0.4413 & 0.9504 \\
\hline F6 & $1.4064^{\mathrm{f}}( \pm 0.3167)$ & $0.3110^{\mathrm{b}}( \pm 0.0236)$ & 0.4443 & 0.9125 \\
\hline F7 & $1.0967^{\mathrm{d}}( \pm 0.0566)$ & $0.3942^{c}( \pm 0.0068)$ & 0.1453 & 0.9954 \\
\hline
\end{tabular}

Mean values \pm standard deviation; $\mathrm{n}=3$. Means followed by the same lowercase letters in the same column do not differ by the Tukey test $(P \geq 0.05)$. $k=$ consistency index $\left(\right.$ Pa $\left.\cdot \mathrm{s}^{\mathrm{n}}\right)$; $n=$ flow behaviour index (dimensionless); RMSE = root mean square error; $\mathrm{R}^{2}=$ coefficient of determination; (F1) strawberry; (F2) red raspberry; (F3) blackberry; (F4) $50 \%$ strawberry and 50\% red raspberry; (F5) 50\% strawberry and 50\% blackberry; (F6) 50\% red raspberry and 50\% blackberry; and (F7) $34 \%$ strawberry, 33\% red raspberry, and 33\% blackberry. 
Based on the presented results, an increase in $k$ was observed and, consequently, in the viscosity of the fruit juice due to the combination of berry fruits. The juice elaborated with strawberry (F1) showed a lower $k$ value; however, when combined with raspberry and blackberry (F4, F5, and F7), an increase in this parameter was observed. Therefore, the presence of strawberry decreases the viscosity of juices, as well as the presence of raspberry and blackberry especially increases the viscosity of berry fruit juice. Such behaviour is represented by Figure 1, which shows the apparent viscosity (Pa.s) as a function of the applied shear rate $\left(\mathrm{s}^{-1}\right)$.

In the rheogram, an evident non-linear trend is visible between the apparent viscosity and shear rate, typical behaviour of non-Newtonian fluids because the slope of the curve decreases with increasing shear rate, characteristic of pseudoplastic fluid. For confirmation of the pseudoplasticity of berry fruit juices, the flow behaviour index $(n)$, which was lower than a unity $(n<1)$ and ranged from 0.2788 to 0.4472 (Table 2), can be observed. The $n$ value indicates the degree of shear-thinning behaviour, and the further this value is from unit value, the more the fluid diverges from Newtonian behaviour (Seth et al., 2018).

Diamante \& Umemoto (2015) compiled and analysed the data from more than 30 recent publications on the properties of fruit- and vegetable-based products (juices and suspensions). The authors used the Power Law model to describe most of the fruit juices, which showed pseudoplastic behaviours $(n<1)$, and they described the interaction between pulp and water as responsible for the different fruit juice rheological properties. Schiassi et al. (2018), in studies with mixed fruit juices from the Cerrado, also noted that the fruit juice data were better described by the Power Law model. In addition, the authors observed that the mixture of two or more fruits positively influenced the viscosity of the final product by combining the characteristics of the fruits, which added value to the mixed juice.

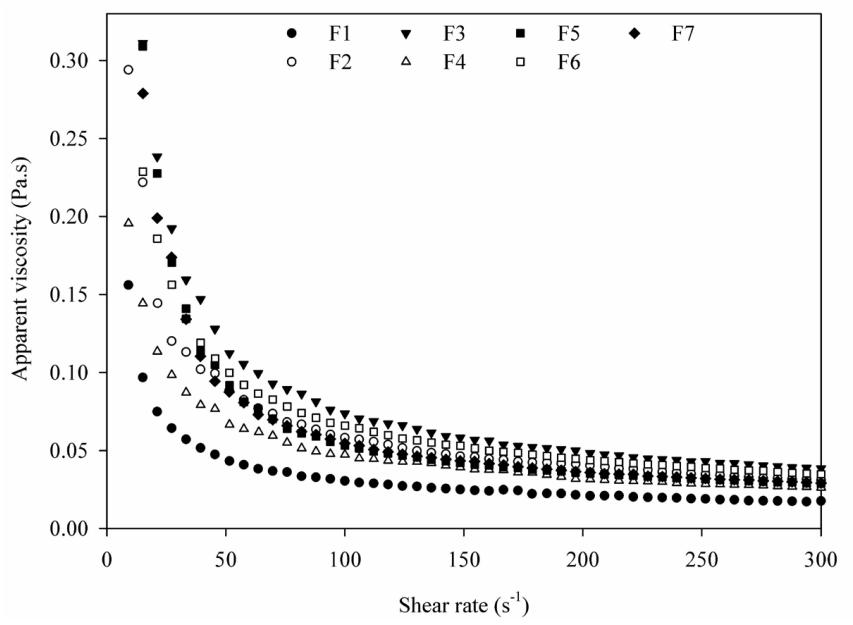

Figure 1. Rheological behaviour of fruit juices at $10{ }^{\circ} \mathrm{C}$ described by the Potency Law model: relation between apparent viscosity $(\mathrm{Pa} \cdot \mathrm{s})$ and shear rate $\left(\mathrm{s}^{-1}\right)$. (F1) strawberry; (F2) red raspberry; (F3) blackberry; (F4) 50\% strawberry and 50\% red raspberry; (F5) 50\% strawberry and $50 \%$ blackberry; (F6) $50 \%$ red raspberry and 50\% blackberry; and (F7) $34 \%$ strawberry, $33 \%$ red raspberry, and $33 \%$ blackberry.
In this context, the rheological parameters of the mixed juices are directly modified by the fruit mixtures, depending on the proportion of each fruit used. Therefore, the product can be developed in order to obtain the type of fluid that meets consumer sensorial acceptance, according to which is desired and available in the market. This fact confirms the advantages of adding two or more fruits rather than an isolated fruit.

\subsection{Physicochemical, physical, and sensory analysis}

Table 3 shows the mean values for the physicochemical, physical, and sensory characteristics results obtained for the fruit juices, where it is possible to note that the samples differentiated from each other $(P \leq 0.05)$ for all attributes evaluated. To represent the data for overall liking and acceptance of the samples, the opinions of the 100 consumers (vectors) on the formulations (F1 to F7) were considered, preferences were correlated with the physicochemical and physical data, an external preference map was plotted (Figure 2).

The juices had $\mathrm{pH}$ values that varied from 3.73 (F1) to 3.48 (F2), and the acidity level ranged from 0.87 (F2) to $0.52 \mathrm{~g}$ citric acid/100 $\mathrm{g}$ (F1). Thus, verification was made that the juice made with $100 \%$ strawberry showed the highest $\mathrm{pH}$ and consequently the lowest acidity, and the formulation elaborated with $100 \%$ red raspberry had the lowest $\mathrm{pH}$ and the highest acidity. The acidity of the red raspberry juice declined and the $\mathrm{pH}$ increased when it was mixed with strawberry and blackberry (F4, F6 and F7). A similar trend was observed in the study by Souza et al. (2014a), who observed different varieties of raspberry pulp (yellow, black and red) and reported that red raspberry acidity decreases and $\mathrm{pH}$ increases when the mixture contains black raspberry or when the three varieties are combined.

The results of soluble solids varied between 7.33 (F1) to $5.67^{\circ} \mathrm{Brix}$ (F3 and F7). In the blackberry juice, the soluble solid content increased when the juice was mixed with strawberry or red raspberry (F5 and F6), and with the union of the three fruits (F7), the soluble solids content did not change $\left(5.67^{\circ} \mathrm{Brix}\right)$. Similar results were also found by Schiassi et al. (2018), who determined that when the three fruit juices were mixed in equal proportions, the solids content was higher than that of the isolated juices. In the elaborated juices, the contents of total soluble solids varied mainly as a function of the amount of sugar present in the fruit and according to Curi et al. (2017), juices that use sweet fruit were more likely to be accepted by consumers.

Regarding the colour, the parameter $\mathrm{L}^{*}$ varied from $30.57(\mathrm{~F} 1)$ to 16.89 (F5), the parameter $\mathrm{C}^{\star}$ ranged from 30.97 (F2) to $18.47(\mathrm{~F} 3)$, and the parameter $h^{\star}$ varied from to 27.89 (F1) to 14.26 (F3). Among the elaborated formulations, the strawberry juice is the one that presented the highest values for the $L^{*}$ and $\mathrm{h}^{\star}$ parameters, being characterized by a shade of light-red colour, and red raspberry juice showed a higher value for $\mathrm{C}^{\star}$, being characterized by a more intense colour. When strawberry juice was mixed with blackberry or red raspberry (F4, F5 and F7), a decrease was observed in the colour parameters $L^{*}$ and $h^{\star}$, and when blackberry juice was mixed with red raspberry or strawberry (F4, F6 and F7), a decrease was observed in the colour parameter value $C^{\star}$. Rodrigues et al. (2017), Curi et al. (2019), and Schiassi et al. (2018), in general, also observed this tendency in mixed fruit products. 
Table 3. Physicochemical aspects, instrumental colour, sensory attributes, antioxidant capacity (ABTS and DPPH methods), total phenolics, total anthocyanins, and ascorbic acid of berry juice.

\begin{tabular}{|c|c|c|c|c|c|c|c|}
\hline Analysis & F1 & F2 & F3 & $\mathrm{F} 4$ & F5 & F6 & F7 \\
\hline \multicolumn{8}{|c|}{ Physicochemical aspects } \\
\hline $\mathrm{pH}$ & $3.73 \pm 0.00^{\mathrm{a}}$ & $3.48 \pm 0.01^{\mathrm{e}}$ & $3.68 \pm 0.01^{\mathrm{b}}$ & $3.60 \pm 0.00^{c}$ & $3.69 \pm 0.01^{\mathrm{b}}$ & $3.56 \pm 0.02^{\mathrm{d}}$ & $3.68 \pm 0.02^{\mathrm{b}}$ \\
\hline Titratable acidity (TA) & $0.52 \pm 0.03^{\mathrm{d}}$ & $0.87 \pm 0.03^{\mathrm{a}}$ & $0.60 \pm 0.06^{\mathrm{bcd}}$ & $0.67 \pm 0.02^{\mathrm{b}}$ & $0.56 \pm 0.01^{\mathrm{cd}}$ & $0.79 \pm 0.01^{\mathrm{a}}$ & $0.63 \pm 0.03^{\text {bc }}$ \\
\hline Soluble Solids (SS) & $7.33 \pm 0.58^{\mathrm{a}}$ & $7.00 \pm 0.00^{\mathrm{ab}}$ & $5.67 \pm 0.58^{\mathrm{b}}$ & $7.00 \pm 0.00^{\mathrm{ab}}$ & $6.67 \pm 0.58^{\mathrm{ab}}$ & $6.67 \pm 0.58^{\mathrm{ab}}$ & $5.67 \pm 0.58^{\mathrm{b}}$ \\
\hline \multicolumn{8}{|l|}{ Instrumental color } \\
\hline $\mathrm{L}^{*}$ & $30.57 \pm 0.53^{\mathrm{a}}$ & $21.30 \pm 0.02^{\mathrm{d}}$ & $20.38 \pm 0.18^{\mathrm{e}}$ & $26.97 \pm 0.53^{\mathrm{b}}$ & $16.89 \pm 0.36^{\mathrm{f}}$ & $24.70 \pm 0.09^{c}$ & $21.04 \pm 0.03^{\mathrm{de}}$ \\
\hline $\mathrm{C}^{*}$ & $29.65 \pm 1.55^{\mathrm{a}}$ & $30.97 \pm 0.05^{\mathrm{a}}$ & $18.47 \pm 0.08^{\mathrm{d}}$ & $30.42 \pm 0.79^{\mathrm{a}}$ & $24.82 \pm 0.40^{\mathrm{b}}$ & $21.40 \pm 0.11^{\mathrm{c}}$ & $20.70 \pm 0.05^{c}$ \\
\hline$h^{*}$ & $27.89 \pm 0.08^{\mathrm{a}}$ & $20.00 \pm 0.05^{c}$ & $14.26 \pm 0.09^{\mathrm{f}}$ & $20.53 \pm 0.24^{\mathrm{b}}$ & $18.03 \pm 0.23^{\mathrm{d}}$ & $14.64 \pm 0.01^{\mathrm{e}}$ & $14.37 \pm 0.00^{\mathrm{ef}}$ \\
\hline \multicolumn{8}{|l|}{ Sensory attributes } \\
\hline Colour & $6.41 \pm 1.82^{\mathrm{ab}}$ & $6.84 \pm 1.66^{\mathrm{a}}$ & $5.97 \pm 2.00^{\mathrm{b}}$ & $6.88 \pm 1.56^{\mathrm{a}}$ & $6.71 \pm 1.67^{\mathrm{a}}$ & $6.51 \pm 1.68^{\mathrm{ab}}$ & $6.46 \pm 1.75^{\mathrm{ab}}$ \\
\hline Flavor & $6.74 \pm 1.65^{\mathrm{a}}$ & $4.66 \pm 2.37^{c}$ & $4.65 \pm 2.13^{c}$ & $6.20 \pm 1.68^{\mathrm{a}}$ & $5.98 \pm 1.87^{\mathrm{ab}}$ & $4.71 \pm 2.13^{c}$ & $5.32 \pm 1.95^{\mathrm{bc}}$ \\
\hline Consistency & $6.66 \pm 1.65^{\mathrm{a}}$ & $6.25 \pm 1.90^{\mathrm{ab}}$ & $4.74 \pm 2.12^{c}$ & $6.72 \pm 1.68^{\mathrm{a}}$ & $6.22 \pm 1.75^{\mathrm{ab}}$ & $5.64 \pm 1.78^{\mathrm{b}}$ & $5.96 \pm 1.83^{\mathrm{ab}}$ \\
\hline Overall liking & $6.83 \pm 1.56^{\mathrm{a}}$ & $5.23 \pm 2.11^{\mathrm{cd}}$ & $4.85 \pm 2.02^{\mathrm{d}}$ & $6.30 \pm 1.84^{\mathrm{ab}}$ & $6.09 \pm 1.81^{\mathrm{ab}}$ & $5.03 \pm 1.97^{\mathrm{cd}}$ & $5.75 \pm 1.95^{\mathrm{bc}}$ \\
\hline \multicolumn{8}{|c|}{ Antioxidant capacity and Bioactive compounds } \\
\hline ABTS & $2.45 \pm 0.01^{\mathrm{e}}$ & $2.81 \pm 0.02^{\mathrm{d}}$ & $5.59 \pm 0.01^{\mathrm{b}}$ & $2.25 \pm 0.01^{\mathrm{f}}$ & $5.21 \pm 0.01^{\mathrm{c}}$ & $6.10 \pm 0.00^{\mathrm{a}}$ & $1.77 \pm 0.02^{\mathrm{g}}$ \\
\hline $\mathrm{DPPH} \mathrm{EC}_{50}$ & $1433.65 \pm 0.30^{\mathrm{a}}$ & $574.65 \pm 0.11^{\mathrm{d}}$ & $450.78 \pm 0.15^{\mathrm{f}}$ & $918.16 \pm 1.91^{\mathrm{b}}$ & $486.41 \pm 0.27^{\mathrm{e}}$ & $367.37 \pm 1.96^{\mathrm{g}}$ & $604.02 \pm 0.66^{c}$ \\
\hline Total phenolic & $134.84 \pm 1.41^{\mathrm{e}}$ & $179.02 \pm 1.59^{c}$ & $224.78 \pm 1.81^{\mathrm{a}}$ & $165.29 \pm 1.94^{\mathrm{d}}$ & $205.44 \pm 1.49^{\mathrm{b}}$ & $227.10 \pm 1.89^{\mathrm{a}}$ & $161.29 \pm 1.75^{\mathrm{d}}$ \\
\hline Total anthocyanins & $77.38 \pm 1.90^{\mathrm{f}}$ & $92.19 \pm 1.73^{\mathrm{ef}}$ & $327.91 \pm 1.03^{\mathrm{a}}$ & $99.87 \pm 1.77^{\mathrm{e}}$ & $290.73 \pm 1.33^{\mathrm{b}}$ & $225.69 \pm 2.70^{c}$ & $138.36 \pm 1.33^{\mathrm{d}}$ \\
\hline Ascorbic acid & $39.07 \pm 0.79^{\mathrm{b}}$ & $34.03 \pm 1.12^{\mathrm{c}}$ & $35.98 \pm 1.13^{c}$ & $36.33 \pm 0.84^{\mathrm{c}}$ & $45.19 \pm 0.54^{\mathrm{a}}$ & $30.22 \pm 0.97^{\mathrm{d}}$ & $30.08 \pm 0.39^{\mathrm{d}}$ \\
\hline
\end{tabular}

Mean values \pm standard deviation; $\mathrm{n}=3$. Means followed by the same lowercase letters in the line do not differ by the Tukey test $(P \geq 0.05)$. TA ( $\mathrm{g}$ citric acid $/ 100 \mathrm{~g}$ f. w.); SS ( $\left.{ }^{\circ} \mathrm{Brix}\right)$. Antioxidant capacity ABTS ( $\mu$ mol TEs/g f. w.) - (f. w. - fresh weight) - ABTS ((2,2'-azino-bis-(3-ethylbenzenothiazoline-6-sulfonic acid); Antioxidant capacity DPPH (EC50 - $g$ f. w./g DPPH) - DPPH (2,2-diphenyl-1-picrylhydrazyl); Total phenolic (mg GAEs/100 g f. w.) - GAE (Gallic acid equivalent); Total anthocyanins (mg of cyanidin 3-glucoside equivalent/100 g f.w.); Ascorbic acid (mg/100 g f. w.). (F1) strawberry; (F2) red raspberry; (F3) blackberry; (F4) 50\% strawberry and 50\% red raspberry; (F5) 50\% strawberry and 50\% blackberry; (F6) 50\% red raspberry and 50\% blackberry; and (F7) 34\% strawberry, 33\% red raspberry, and 33\% blackberry.

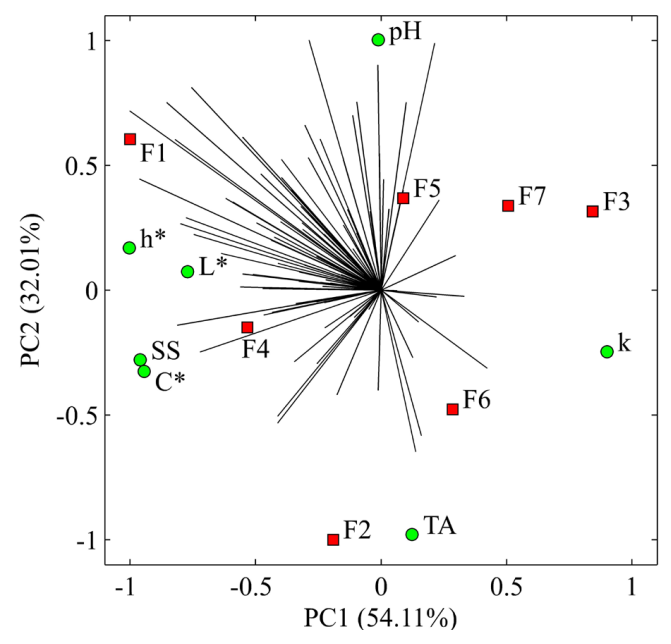

Figure 2. External preference map for sensory attributes (overall liking), physicochemical aspects $(\mathrm{pH}, \mathrm{TA}$ and $\mathrm{SS})$ and physical aspects $\left(\mathrm{L}^{\star}, \mathrm{C}^{\star}\right.$, $\mathrm{h}^{\star}$, and $k$ ). 1st Principal Component 1 (PC1), 2nd Principal Component (PC2), Titratable acidity (TA), soluble solids (SS) and consistency index ( $k$ ). (F1) strawberry; (F2) red raspberry; (F3) blackberry; (F4) $50 \%$ strawberry and 50\% red raspberry; (F5) 50\% strawberry and 50\% blackberry; (F6) 50\% red raspberry and 50\% blackberry; and (F7) $34 \%$ strawberry, 33\% red raspberry, and 33\% blackberry.

Based on Table 3 and Figure 2, the juices containing 100\% or $50 \%$ of strawberry (F1, F4 and F5) were preferred among the tasters, differing statistically from the others $(P \leq 0.05)$. The most accepted formulations showed scores between the hedonic terms 'liked slightly' to 'moderately liked'. The other less accepted formulations had average scores that varied between the hedonic terms 'disliked slightly' and 'liked slightly', being juices composed of red raspberry and blackberry alone (F2 and F3) or in combination (F6 and F7). This suggests that the red raspberry and blackberry contributed negatively to acceptance of the juice when they are provided alone (F2 and F3) or in combination (F6). However, when this fruit was combined with strawberry (F4 and F5), greater sensory acceptance was observed.

In similar studies by Pereira et al. (2015), Curi et al. (2017), and Schiassi et al. (2018) involving mixed juice with different types of fruits and in the studies of Souza et al. (2014a), Rodrigues et al. (2017), Curi et al. (2019), and Schiassi et al. (2019), who developed mixed fruit jellies and juices, noted that when elaborated with isolated fruits were not well accepted among tasters but, in general, presented better acceptance when combined.

A correlation of the physical and physicochemical characteristics and sensory parameters (Figure 2 and Table 3 ) show that less accepted formulations (F2, F3, F6, and F7), which differed statistically from the others $(P \leq 0.05)$, were characterized for presenting generally higher values of acidity and apparent viscosity. High acidity and viscosity also contributed to lower acceptance of the mixed fruit juices in the study of Schiassi et al. (2018). Thus, indicators are that consumers prefer juices with low acidity and viscosity.

\subsection{Bioactive compounds and antioxidant capacity}

Table 3 shows the data for antioxidant activity, total phenolic compounds, total monomeric anthocyanins and ascorbic acid. To facilitate the results visualization, another more detailed analysis 
of these parameters was performed by principal component analysis (PCA), as presented in Figure 3. Through Table 3 and Figure 3, it is possible to observe that the juices differed in terms of antioxidant activity and the evaluated bioactive compounds.

Relative to the antioxidant activity, the juices presented values ranging from 6.10 (F6) to $1.77 \mu \mathrm{mol}$ TEs/g f.w. (F7) for the ABTS method and 1433.65 (F1) to $367.37 \mathrm{~g}$ f.w./g DPPH (F6) for the DPPH method. In general, the F6 formulation presented the greatest antioxidant capacity, overlapping even in the content of the isolated fruit juices, demonstrating a possible synergistic effect for this increase in antioxidant activity.

The juices presented total phenolic and anthocyanin contents ranging from 227.10 (F6) to $134.84 \mathrm{mg} \mathrm{GAE} / 100 \mathrm{~g}$ f.w. (F1) and 327.91 (F3) to $77.38 \mathrm{mg}$ of cyanidin 3-glucoside equivalent/100 g f.w. (F1), respectively. According to the classification proposed by Vasco et al. (2008), all juices presented medium content; however, the formulations F3 and F6 stood out for having the highest total phenolic content, and F3 still has the highest anthocyanin content. As observed for the antioxidant activity, certain combinations give rise to juices with a higher content of phenolics and anthocyanin than when elaborated with the isolated fruits, as is the case, for example, with the F6 formulation for total phenolics.

For the vitamin $\mathrm{C}$ content, the variation range was 45.19 (F5) to $30.08 \mathrm{mg} / 100 \mathrm{~g}$ f.w. (F7). According to the classification of Ramful et al. (2011), all formulations can be considered to have medium ascorbic acid contents. The ascorbic acid content is significantly higher in the juices that are mixtures of two fruits

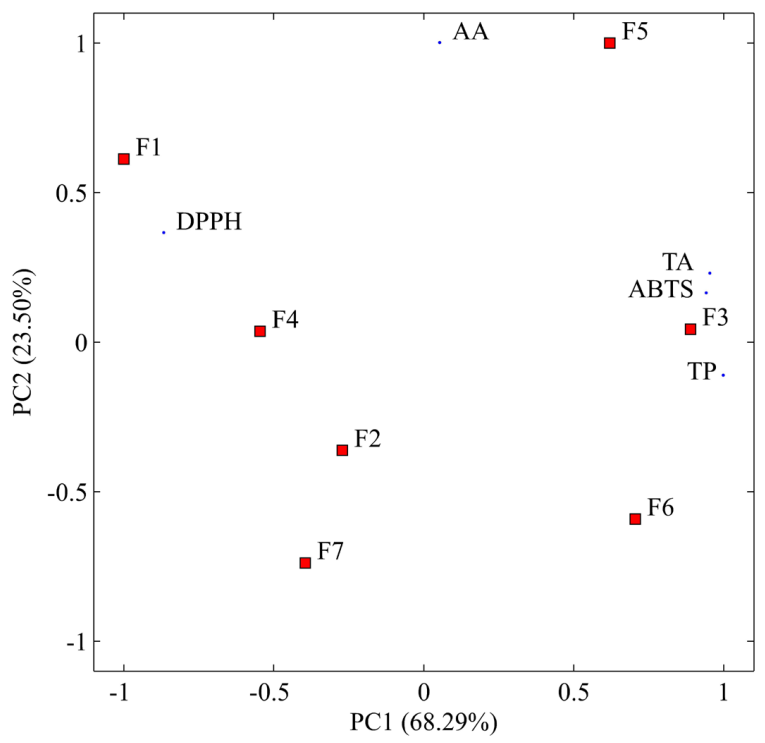

Figure 3. Principal component analysis (PCA) for berry juice formulations, bioactive compounds, and antioxidant activity. 1st Principal Component 1 (PC1), 2nd Principal Component (PC2), Antioxidant capacity - ABTS ((2,2'-azino-bis-(3-ethylbenzenothiazoline-6-sulfonic acid)); Antioxidant capacity - DPPH EC (2, $_{50}$-diphenyl-1-picrylhydrazyl); Phenolic total (TP); Total anthocyanins (TA); Ascorbic acid (AA). (F1) strawberry; (F2) red raspberry; (F3) blackberry; (F4) 50\% strawberry and $50 \%$ red raspberry; (F5) 50\% strawberry and 50\% blackberry; (F6) $50 \%$ red raspberry and 50\% blackberry; and (F7) $34 \%$ strawberry, $33 \%$ red raspberry, and $33 \%$ blackberry. compared with the juices of a single fruit, reporting the occurrence of a synergistic effect. According to Wang et al. (2011), the synergistic effect occurs when the effect is greater than the sum of the individual components. A similar trend was observed in the studies by Seo et al. (2016), Rodrigues et al. (2017), Curi et al. (2017, 2019), and Schiassi et al. (2019).

\subsection{Optimization of mixed fruit juice}

The sensory aspects (colour, flavor, consistency, and overall liking) of the mixed berry juices were converted into a desirability function for the optimization of the formulations. Regarding the sensory variables, the quadratic model for the desirability function was adjusted; the model is expressed in Equation 4. $\mathrm{R}^{2}$ values greater than 0.7 , significant regressions $(P \leq 0.05)$, and no significant lack-of-fit $(P \geq 0.05)$ are presented. This indicates that the models employed were adequate for such predictions (Henika, 1982).

$D_{s}=0.73 X_{1}^{*}+0.38 X_{2}^{*}+0.13 X_{3}+$ $0.53 X_{1} X_{2}+0.62 X_{1} X_{3}-0.05 X_{2} X_{3}$

where $X_{1}$ is the mass fraction of the strawberry juice; $X_{2}$ is the mass fraction of the red raspberry juice; and $X_{3}$ is the mass fraction of the blackberry juice. The ${ }^{\star}$ symbol indicates that the coefficient was significant $(P \leq 0.05)$. Based on the predicted equation of sensory desirability, a contour curve (Figure 4) was generated, and an optimal region was derived. This region represents the bands with the best colour, flavor, consistency, and overall linking.

Figure 4 shows the ideal juice elaboration region that has wide acceptance: the range of these fruits in the formulations should be between 50 and $100 \%$ for strawberry, 0 and $65 \%$ for red raspberry, and 0 to $40 \%$ for blackberry. This is because juices made with strawberry, in general, were the most accepted among tasters. High sensorial acceptance of strawberry jellies was also reported by Curi et al. (2016).

In relation to the nutritional aspects (bioactive compounds and antioxidant activity) were not adjusted to any model, i.e.,

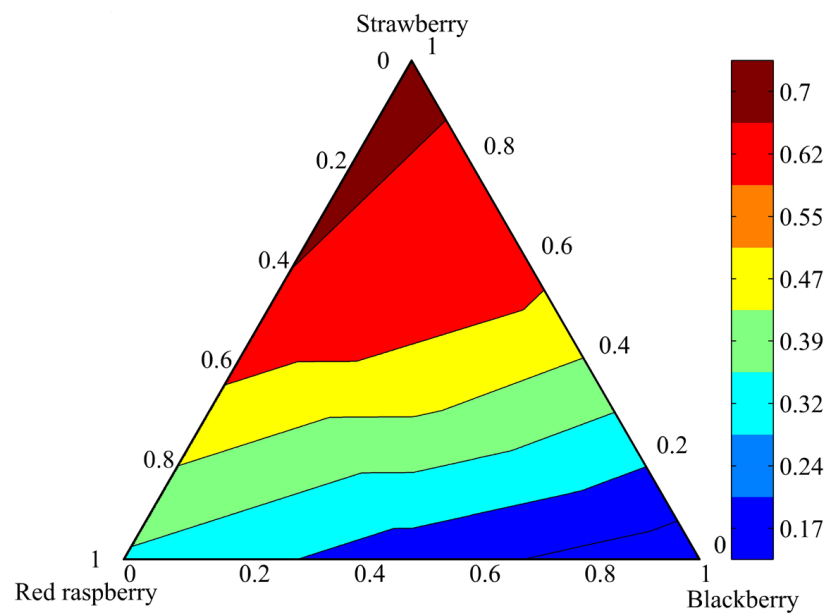

Figure 4. Contour curve for sensory desirability functions for berry juices. 
the lack of fit for all models tested were significant. However, through the PCA, verification was possible in general that the formulations containing blackberry stood out nutritionally, presenting the highest antioxidant activity by the ABTS and DPPH methods (F6), ascorbic acid (F5), phenolic compounds and total anthocyanins (F3). So, based on that, the use of the maximum limit of blackberry is recommended within the optimal region of acceptance, that is, $40 \%$. The following ratio is recommended for the remaining 60\%: 50-60\% strawberry and $0-10 \%$ red raspberry. To achieve the highest sensory acceptance, at least $50 \%$ strawberry is required. The use of raspberry in the composition will influence other factors such as cost.

The fruit blend may be sensory and nutritionally advantageous because it can increase the content of vitamins, minerals, and soluble solids, improve colour and consistency, and balance weak, mild and strong flavours, mainly with high acidity, astringency, or the bitterness of certain fruits (Curi et al., 2017; Schiassi et al., 2018). As observed in this work, the formulation of products made using two or more fruits is indeed of interest to consumers.

\section{Conclusions}

The mixture of two or more fruits influences the physical, physicochemical, rheological, nutritional, and sensorial characteristics of juice because certain combinations may increase the nutritional and sensory values of the juice. According to optimization, juices with higher sensory and nutritional quality should contain 50-60\% strawberry, 40\% blackberry, and 0-10\% raspberry.

\section{Acknowledgements}

This study was financed in part by the Coordenação de Aperfeiçoamento de Pessoal de Nível Superior - Brasil (CAPES) - Finance Code 001. The authors wish to thank the Conselho Nacional de Desenvolvimento Científico e Tecnológico - Brasil $(\mathrm{CNPq})$, and the Fundação de Amparo à Pesquisa do Estado de Minas Gerais - Brasil (FAPEMIG) for their financial report.

\section{References}

Alvares, C. A., Stape, J. L., Sentelhas, P. C., Gonçalves, M. J. L., \& Sparovek, G. (2013). Köppen's climate classification map for Brazil. Meteorologische Zeitschrift, 22(6), 711-728. http://dx.doi. org/10.1127/0941-2948/2013/0507.

Brand-Williams, W., Cuvelier, M. E., \& Berset, C. (1995). Use of a free radical method to evaluate antioxidant activity. Food Science and Technology, 28(1), 25-30. http://dx.doi.org/10.1016/S00236438(95)80008-5.

Brasil, Ministério da Saúde, Secretaria de Vigilância Sanitária. (2009, July 14). Aprova o regulamento de registro, a padronização, a classificação, a inspeção e a fiscalização da produção e do comércio de bebidas (Decreto n 6.871 de 4 de junho de 2009). Diário Oficial [da] República Federativa do Brasil. Retrieved from https://www. anvisa.gov.br

Chauhan, O. P., Archana, B. S., Singh, A., Raju, P. S., \& Bawa, A. S. (2014). A refreshing beverage from mature coconut water blended with lemon juice. Journal of Food Science and Technology, 51(11), 33553361. http://dx.doi.org/10.1007/s13197-012-0825-6. PMid:26396331.
Cornell, J. A. (2002). Experiment with mixtures: design, models and analysis of mixtures data. New York: John Wiley \& Sons. http:// dx.doi.org/10.1002/9781118204221.

Curi, P. N., Almeida, A. B., Pio, R., Lima, L. C. O., Nunes, C. A., \& Souza, V. R. (2019). Optimization of native Brazilian fruit jelly through desirability-based mixture design. Food Science and Technology, 39(2), 388-395. http://dx.doi.org/10.1590/fst.31817.

Curi, P. N., Almeida, A. B., Tavares, B. S., Nunes, C. A., Pio, R., Pasqual, M., \& Souza, V. R. (2017). Optimization of tropical fruit juice based on sensory and nutritional characteristics. Food Science and Technology, 37(2), 308-314. http://dx.doi.org/10.1590/1678-457x.24716.

Curi, P. N., Tavares, B. S., Almeida, A. B., Pio, R., Peche, P. M., \& Souza, V. R. (2016). Influence of subtropical region strawberry cultivars on jelly characteristics. Journal of Food Science, 81(6), S1515-S1520. http://dx.doi.org/10.1111/1750-3841.13325. PMid:27115540.

Diamante, L., \& Umemoto, M. (2015). Rheological properties of fruits and vegetables: a review. International Journal of Food Properties, 18(6), 1191-1210. http://dx.doi.org/10.1080/10942912.2014.898653.

Food and Agriculture Organization of the United Nations - FAO, World Health Organization - WHO. (2005). Codex Alimentarius: International Food Standards: Codex Stan 247. Rome. Retrieved from http://www.fao.org/fao-who-codex alimentarius/codex_247

Gennadios, A., Weller, C. L., Hanna, M. A., \& Froning, G. W. (1996). Mechanical and barrier properties of egg albumen films. Journal of Food Science, 61(3), 585-589. http://dx.doi.org/10.1111/j.1365-2621.1996. tb13164.x.

Gomes-Rochette, N. F., Da Silveira Vasconcelos, M., Nabavi, S. M., Mota, E. F., Nunes-Pinheiro, D. C., Daglia, M., \& De Melo, D. F. (2016). Fruit as potent natural antioxidants and their biological effects. Current Pharmaceutical Biotechnology, 17(11), 986-993. http:// dx.doi.org/10.2174/1389201017666160425115401. PMid:27109905.

Henika, G. R. (1982). Use of response surface methodology in sensory evaluation. Food Technology, 36(11), 96-101.

Hidalgo, G. I., \& Almajano, M. P. (2017). Red fruits: extraction of antioxidants, phenolic Content, and radical scavenging determination: a review. Antioxidants, 6(1), 7.http://dx.doi.org/10.3390/antiox6010007. PMid:28106822.

Instituto Adolfo Lutz - IAL. (2008). Procedimentos e determinações gerais: métodos físico-químicos para análise de alimentos. São Paulo: IAL.

Larrauri, J. A., Rupérez, P., \& Saura-Calixto, F. (1997). Effect of drying temperature on the stability of polyphenols and antioxidant activity of red grape pomace peels. Journal of Agricultural and Food Chemistry, 45(4), 1390-1393. http://dx.doi.org/10.1021/jf960282f.

MacFie, H. J., Bratchell, N., Greenhoff, K., \& Vallis, L. V. (1989). Designs to balance the effect of order of presentation and first-order carryover effects in hall tests. Journal of Sensory Studies, 4(2), 129-148. http://dx.doi.org/10.1111/j.1745-459X.1989.tb00463.x.

Manganaris, G. A., Goulas, V., Vicente, A. R. V., \& Terry, L. A. (2014). Berry antioxidants: small fruits providing large benefits. Journal of the Science of Food and Agriculture, 94(5), 825-833. http://dx.doi. org/10.1002/jsfa.6432. PMid:24122646.

Newhart, B. (2019). The last 30 years in beverages: how have consumers changed? Retrieved from https://www.beveragedaily.com/ Article/2019/09/16/30-years-in-beverage-how-have-consumerschanged

Nunes, C. A., Freitas, M. P., Pinheiro, A. C. M., \& Bastos, S. C. (2012). Chemoface: a novel free user-friendly interface for chemometrics. Journal of the Brazilian Chemical Society, 23(11), 2003-2010. http:// dx.doi.org/10.1590/S0103-50532012005000073. 
Nunes, C. A., Pinheiro, A. C. M., \& Bastos, S. C. (2011). Evaluating consumer acceptance tests by three-way internal preference mapping obtained by parallel factor analysis (PARAFAC). Journal of Sensory Studies, 26(2), 167-174. http://dx.doi.org/10.1111/j.1745459X.2011.00333.x.

Olas, B. (2018). Berry phenolic antioxidants: implications for human health. Frontiers in Pharmacology, 9(A78), 1-14. http://dx.doi. org/10.3389/fphar.2018.00078.

Pelegrine, D. H. G., Andrade, M. S., \& Nunes, S. H. (2015). Elaboração de geleias a partir de misturas binárias compostas pelas polpas de laranja e acerola. Ciência e Natura, 37(1), 124-129. http://dx.doi. org/10.5902/2179460X15051.

Pereira, A. C. S., Wurlitzer, N. J., Dionísio, A. P., Lacerda, S. M. V., Rocha, B. M. S., Elesbão, A. R., \& Montenegro, B. I. (2015). Synergistic, additive and antagonistic effects of fruit mixtures on total antioxidante capacities and bioactive compounds in tropical fruit juices. Archivos Latinoamericanos de Nutricion, 65(2), 119-127. PMid:26817384.

Pinheiro, A. C. M., Nunes, C. A., \& Vietoris, V. (2013). SensoMaker: a tool for sensorial characterization of food products. Ciência $e$ Agrotecnologia, 37(3), 199-201. http://dx.doi.org/10.1590/S141370542013000300001 .

Prado, F. C., Lindner, J. D., Inada, J., Thomaz-Soccol, V., Brar, S. K., \& Soccola, C. R. (2015). Development and evaluation of a fermented coconut water beverage with potential health benefits. Journal of Functional Foods, 12, 489-497. http://dx.doi.org/10.1016/j. jff.2014.12.020.

Ramful, D., Tarnus, E., Aruoma, O. I., Bourdon, E., \& Bahorun, T. (2011). Polyphenol composition, vitamin C content and antioxidant capacity of Mauritian citrus fruit pulps. Food Research International, 44(7), 2088-2099. http://dx.doi.org/10.1016/j.foodres.2011.03.056.

Re, R., Pellegrini, N., Proteggente, A., Pannala, A., Yang, M., \& RiceEvans, C. (1999). Antioxidant activity applying an improved ABTS radical cation decolorization assay. Free Radical Biology \& Medicine, 26(9-10), 1231-1237. http://dx.doi.org/10.1016/S0891-5849(98)003153. PMid:10381194.

Rodrigues, L. M., Souza, D. F., Silva, E. A., Oliveira, T. O., \& Lima, J. P. (2017). Physical and chemical characterization and quantification of bioactive compounds in berries and berry jams. Semina: Ciências Agrárias, 38(4), 1853-1864. http://dx.doi.org/10.5433/16790359.2017v38n4p1853.

SAS Institute. (2016). SAS University Edition vApp. Cary: SAS Institute. Retrieved from http://www.sas.com/pt_br/software/universityedition.html

Schiassi, M. C. E. V., Lago, A. M. T., Souza, V. R., Meles, J. S., Resende, J. V., \& Queiroz, F. (2018). Mixed fruit juices from Cerrado: optimization based on sensory properties, bioactive compounds and antioxidant capacity. British Food Journal, 120(10), 2334-2348. http://dx.doi. org/10.1108/BFJ-12-2017-0684.

Schiassi, M. C. E. V., Salgado, D. L., Meirelles, B. S., Lago, A. M. T., Queiroz, F., Curi, P. N., Pio, R., \& Souza, V. R. (2019). Berry jelly: optimization through desirability-based mixture design. Journal of Food Science, 84(6), 1522-1528. http://dx.doi.org/10.1111/17503841.14634. PMid:31120586.
Seo, J. Y., Jang, J. H., Kim, J. S., Kim, E. J., \& Kim, J. S. (2016). Development of low-sugar antioxidant jam by a combination of anthocyanin-rich berrie. Applied Biological Chemistry, 59(2), 305-312. http://dx.doi. org/10.1007/s13765-016-0152-0.

Seth, D., Mishra, H. N., \& Deka, S. C. (2018). Effect of hydrocolloids on the physic chemical and rheological properties of reconstituted sweetened yoghurt powder. Journal of the Science of Food and Agriculture, 98(5), 1696-1702. http://dx.doi.org/10.1002/jsfa.8641. PMid:28853145.

Sobhana, A., Mathew, J., Ambili, A. A., \& Mredhula, R. C. (2015), Blending of cashew apple juice with fruit juices and spices for improving nutritional quality and palatability. Acta Horticulturae, (1080), 369-375. http://dx.doi.org/10.17660/ActaHortic.2015.1080.49.

Souza, V. R., Pereira, P. A. P., Pinheiro, A. C. M., Nunes, C. A., Silva, T. L. T., Borges, S. V., \& Queiroz, F. (2012). Multivariate approaches for optimization of the acceptance: optimization of a Brazilian Cerrado fruit jam using mixture design and Parallel factor analysis. Journal of Sensory Studies, 27(6), 417-424. http://dx.doi.org/10.1111/joss.12005.

Souza, V. R., Pereira, P. A. P., Pinheiro, A. C. M., Nunes, C. A., Pio, R., \& Queiroz, F. (2014a). Evaluation of the jelly processing potential of raspberries adapted in Brazil. Journal of Food Science, 79(3), 407412. http://dx.doi.org/10.1111/1750-3841.12354. PMid:24467459.

Souza, V. R., Pereira, P. A. P., Silva, T. L. T., Lima, L. C. O. L., Pio, R., \& Queiroz, F. (2014b). Determination of the bioactive compounds, antioxidant activity and chemical composition of Brazilian blackberry, red raspberry, strawberry, blueberry and sweet cherry fruits. Food Chemistry, 156, 362-368. http://dx.doi.org/10.1016/j. foodchem.2014.01.125. PMid:24629981.

Stone, H., Bleibaum, R., \& Thomas, H. A. (2012). Sensory evaluation practices. New York: Academic Press.

Strohecker, R., \& Henning, H. M. (1967). Analisis de vitaminas: métodos comprovados. Madrid: Paz Montalvo.

SYSTAT Software Inc. (2008). SigmaPlot for Windows. San Jose: SYSTAT Software Inc. Retrieved from https://systatsoftware.com/products/ sigmaplot/sigmaplot-product-updates

Vasco, C., Ruales, J., \& Kamal-Eldin, A. (2008). Total phenolic compounds and antioxidant capacities of major fruits from Ecuador. Food Chemistry, 111(4), 816-823. http://dx.doi.org/10.1016/j.foodchem.2008.04.054.

Wang, S., Meckling, K. A., Marcone, M. F., Kakuda, Y., \& Tsao, R. (2011). Synergistic, additive, and antagonistic effects of food mixtures on total antioxidant capacities. Journal of Agricultural and Food Chemistry, 59(3), 960-968. http://dx.doi.org/10.1021/jf1040977. PMid:21222468.

Waterhouse, A. L. (2002). Polyphenolics: determination of total phenolics in current protocols in food analytical chemistry. New York: John Wiley \& Sons.

Wrolstad, R. E. (1993). Color and pigment analyses in fruit products. Corvallis: Oregon State University.

Yousefi, G., Yousefi, S., \& Emam-Djomeh, Z. (2013). A comparative study on different concentration methods of extracts obtained from two raspberries (Rubus idaeus L.) cultivars: evaluation of anthocyanins and phenolics contents and antioxidant activity. International Journal of Food Science \& Technology, 48(6), 11791186. http://dx.doi.org/10.1111/ijfs.12073. 